\title{
The Functional Role of Garlic and Bioactive Components in Cardiovascular and Cerebrovascular Health: What We Do Know
}

\author{
Chidiebere Emmanuel Ugwu, Stephen Monday Suru \\ Department of Human Biochemistry, Faculty of Basic Medical Sciences, Nnamdi Azikiwe University Awka, Nnewi Campus, Nnewi, Nigeria \\ Email:ugwuchidiksu@yahoo.com,ce.ugwu@unizik.edu.ng,sm.suru@unizik.edu.ng
}

How to cite this paper: Ugwu, C.E. and Suru, S.M. (2016) The Functional Role of Garlic and Bioactive Components in Cardiovascular and Cerebrovascular Health: What We Do Know. Journal of Biosciences and Medicines, 4, 28-42.

http://dx.doi.org/10.4236/jbm.2016.410004

Received: July 15, 2016

Accepted: October 16, 2016

Published: October 19, 2016

Copyright $\odot 2016$ by authors and Scientific Research Publishing Inc. This work is licensed under the Creative Commons Attribution International License (CC BY 4.0).

http://creativecommons.org/licenses/by/4.0/

\begin{abstract}
Cardiovascular disease is a complex and multifactorial disease strongly associated with hypercholesterolemia, hypertension, reduced fibrinolysis, increased blood-clotting time and increased platelet aggregation. Among other confounding factors, oxidative damage is a major factor in cardiovascular and cerebrovascular diseases. The use of garlic in folkloric medicine highlights the potential role in either preventing or delaying cardiovascular disease. Contemporary research reveals how garlic and bioactive components modulate the risk factors of cardiovascular and cerebrovascular diseases thus tending towards validating a measure of folkloric claims concerning the functional efficacy of garlic. This review seeks to elucidate contemporary research attempt towards the validation of the role of garlic and bioactive components, mechanisms of action involved and to define its ultimate role in the prevention and treatment of cardiovascular and cerebrovascular diseases. Some contradictory claims exist possibly due to the use of different experimental protocols/formulations/dosages of garlic. Overwhelming commonality of positive cardiovascular and cerebrovascular responses reside among research studies thus offering compelling evidence in supports of the beneficial health effects of garlic and components.
\end{abstract}

\section{Keywords}

Garlic, Cardiovascular, Cerebrovascular, Bioactive Components

\section{Introduction}

Cardiovascular disease (CVD) is a class of diseases that involve the heart and blood vessels [1]. Cardiovascular disease includes coronary artery diseases (CAD) such as angina and myocardial infarction. Other CVDs are stroke, hypertensive heart disease, 
rheumatic heart disease, cardiomyopathy, heart arrhythmia, congenital heart disease, valvular heart disease, carditis, aortic aneurysms, peripheral artery disease, and venous thrombosis [1].

The underlying mechanisms vary depending on the disease in question. Coronary artery disease, stroke, and peripheral artery disease involve atherosclerosis. This may be caused by high blood pressure, smoking, diabetes, lack of exercise, obesity, high blood cholesterol, poor diet, and excessive alcohol consumption, among others [2]. It is estimated that $90 \%$ of CVD is preventable. Prevention of atherosclerosis is by decreasing risk factors through: healthy eating, exercise, avoidance of tobacco smoke and limiting alcohol intake.

A cerebrovascular disease is a vascular disease of the cerebral circulation. Arteries supplying oxygen to the brain are affected resulting in one of a number of cerebrovascular diseases. Most commonly this is a stroke or mini-stroke and sometimes can be a haemorrhagic stroke. Hypertension (high blood pressure) is the most important contributing cause because it damages the blood vessel lining exposing collagen where platelets aggregate to initiate a repair. If maintained hypertension can change the structure of blood vessels. Blood pressure affects blood flow in narrowed vessels causing ischemic stroke, a rise in blood pressure can cause tearing of vessels leading to intracranial haemorrhage. A stroke usually presents with an abrupt onset of a neurologic deficit, attributable to a focal vascular lesion. The neurologic symptoms manifest within seconds because neurons lack glycogen, so energy failure is rapid.

It has become increasingly important to integrate complementary and alternative medicine into the treatment of cardiovascular and cerebrovascular diseases. The interest in the use of alternative and complementary medicine in the treatment of CVDs has increased in recent time [3] [4]. There are many adult populations with uncontrolled blood pressure because many standard antihypertensive drugs are not usually effective [3].

Garlic (Allium sativum Linn) has been used by man in different cultures for hundreds of years as foodstuffs, condiments, as flavourings and in folk medicine. It has numerous biological activities that are attributed to its rich content of different volatile organosulfur compound (OSC) and other phytochemicals that work in synergy by combination of mechanisms for substance acting on various molecular targets [5]-[8].

Hundreds of chemical substances are present in garlic or extracts. Some basic sulphur-containing bioactive constituents in whole, intact garlic are the $\gamma$-glutamyl- $S$ alk(en)yl-L-cysteines and $S$-alk(en)yl-L-cysteine sulphoxides, including alliin. The $\gamma$ glutamyl peptides are biosynthetic intermediates for corresponding cysteine sulphoxides [9] [10]. Whole intact garlic typically contains $\sim 1 \%$ alliin, together with $(+)-S$-methylL-cysteine sulphoxide (methiin) and (+)-S-(trans-1-propenyl)-L-cysteine sulphoxide. $S$ (2-carboxypropyl) glutathione, $\gamma$-glutamyl- $S$-allyl-L-cysteine, $\gamma$-glutamyl- $S$-(trans-1-propenyl)-L-cysteine and $\gamma$-glutamyl- $S$-allyl-mercapto-L-cysteine are also reported to be present in garlic cloves [10] [11].

The health benefits of garlic likely arise from a wide variety of components, possibly 
working synergistically. Moreso, it is proposed that the prediction of potential health benefit(s) from garlic is largely dependent on the efficacy and safety of the garlic preparations, which are also contingent on the processing methods employed [12]. The complex chemistry of garlic makes it plausible that variations in processing can yield quite different preparations. Highly unstable thiosulphinates, such as allicin, disappear during processing and are quickly transformed into a variety of organosulphur components. Although there are many garlic supplements commercially available, they fall into one of four categories, which are dehydrated garlic powder, garlic oil, garlic oil macerate and aged garlic extract (AGE).

Clinical and experimental studies on the acclaimed biological properties of garlic has been divergent due to different garlic preparations used, unidentifiable active components and their bioefficacy, duration of trials among other factors [13] [14]. There is also the problem of using whole extract preparations rather than the isolated constituents. It therefore becomes difficult to validate the folkloric use of garlic in the traditional society. This review seeks to elucidate contemporary research attempt towards the validation of the role of garlic and bioactive components, mechanisms of action involved and to define its ultimate role in the prevention and treatment of cardiovascular and cerebrovascular diseases. Some contradictory claims exist possibly due to the use of different experimental protocols/formulations/dosage of garlic.

\section{Effects of Garlic on Cardiovascular and Cerebrovascular Diseases}

Cardiovascular diseases (CVD) can be described as chronic diseases in humans. It has different aetiology ranging from hypercholesterolemia, diabetes mellitus, hypertension, increased oxidation damage and smoking [2]. The oxidative modification of lipids, especially LDL, has been majorly implicated in the onset and development of cardiovascular and cerebrovascular diseases [15] [16]. The oxidation of lipids modifies the membrane system and affects their functions causing reduced fluidity and inactivation of membrane-bound enzymes and receptors. The red blood cells are also damaged and endothelial cells are injured, increasing blood vessel fragility. The oxidation of LDL enhances the growth of fatty streaks inside the blood vessel walls [17] and the emergence of plaque [18]. Toxic aldehydes formed in lipid oxidation react with the apoprotein B of the LDL particle to produce a novel epitome that is recognized by macrophage receptors, resulting in the formation of foam cells and atherosclerotic plaques and increased risk of heart disease and stroke [16].

Garlic has been appraised as a remedy for the treatment and prevention of a number of diseases such as cardiovascular and cerebrovascular diseases, as well as other metabolic diseases, hyperlipidaemia and diabetes (Figure 1). Several functional health effects elicited by garlic are strongly attributable to its bioactive components particularly the sulphur-containing compounds such as S-allyl cysteine (SAC) diallyl disulphide (DADS), and S-methyl cysteine sulphoxide (Figure 2 and Table 1). Various studies have revealed that different garlic preparations elicit different biological health effects based on 


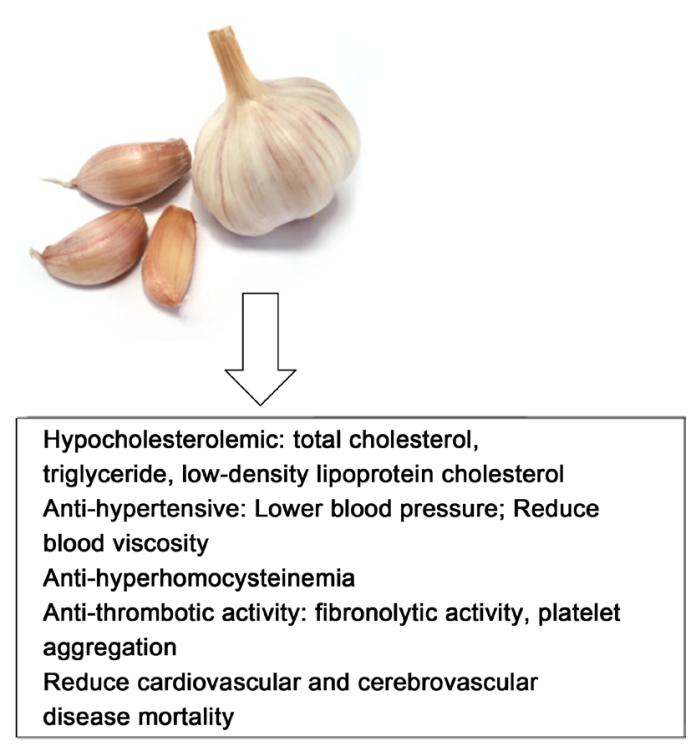

Figure 1. General scheme showing several roles of garlic in cardiovascular and cerebrovascular diseases.
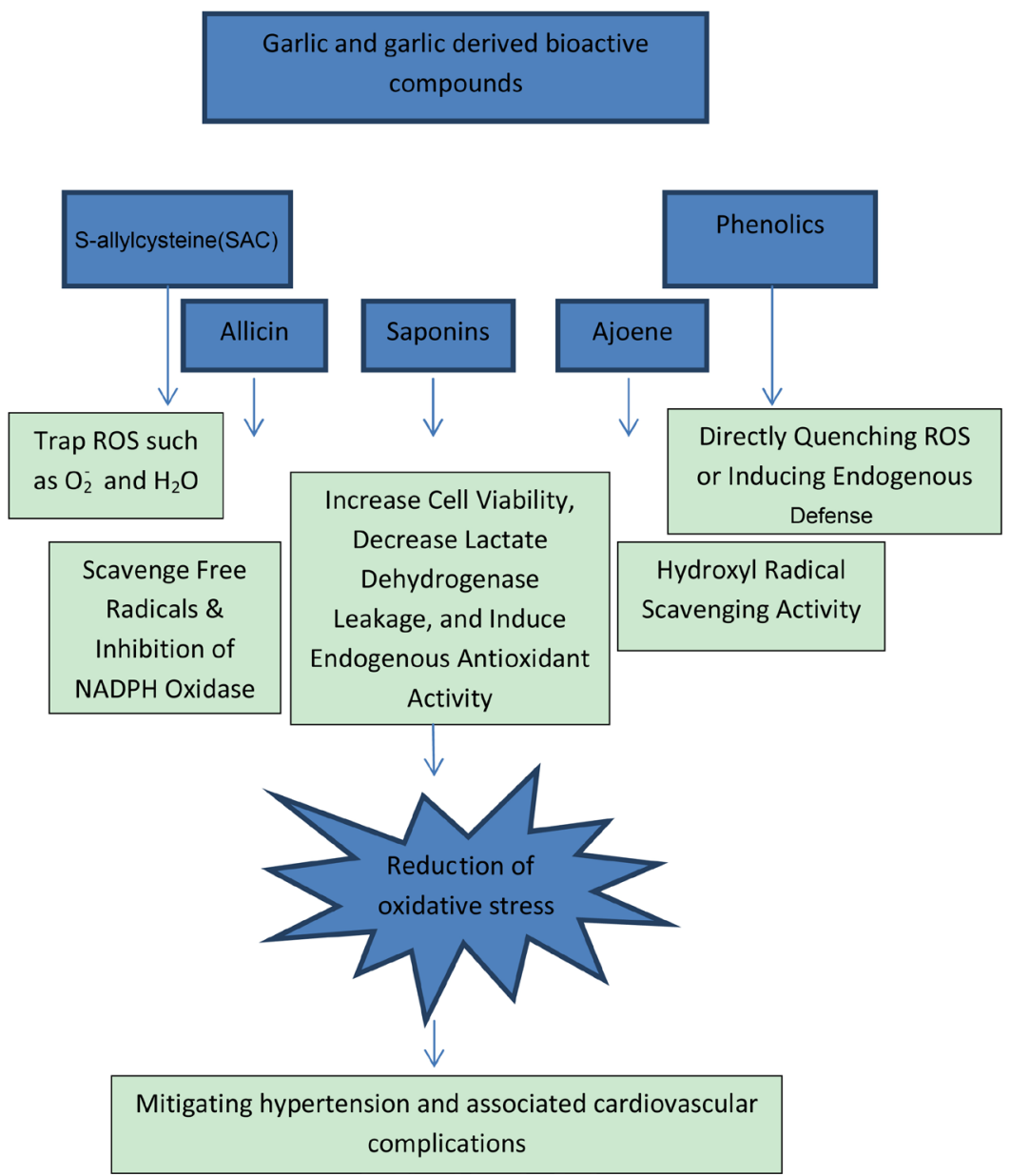

Figure 2. Reduction of oxidative stress by garlic and bioactive components in hypertension and associated cardiovascular complications. Source: Shouk et al. [76]. 
Table 1. Cardiovascular and cerebrovascular organosulfur compounds in garlic extract.

\begin{tabular}{|c|c|c|}
\hline Organosulfur compounds & Reported Cardiovascular activity & Reference \\
\hline Diallyl disulfide (DADS) & $\begin{array}{l}\text { Suppress oxidized LDL-induced vascular cell } \\
\text { adhesion. }\end{array}$ & [7] \\
\hline S-allyl cysteine (SAC). & $\begin{array}{c}\text { Antihypertensive and cardioprotective in the } \\
\text { presence of captopril. }\end{array}$ & [77] \\
\hline $\begin{array}{l}\text { S-ethyl cysteine (SEC), S-propyl } \\
\text { cysteine (SPC). }\end{array}$ & $\begin{array}{l}\text { Inhibition of cholesterol synthesis by } 40-60 \\
\text { percent. }\end{array}$ & {$[42]$} \\
\hline $\begin{array}{c}\gamma \text {-glutarmyl-S-allyl cysteine (GSAC), } \\
\gamma \text {-glutarmyl-S-methyl cysteine (GSMC), } \\
\gamma \text {-glutarmyl-S-propyl cysteine (GSPC), }\end{array}$ & $\begin{array}{l}\text { Inhibition of cholesterol synthesis by } 40-60 \\
\text { percent. }\end{array}$ & {$[42]$} \\
\hline $\begin{array}{l}\text { Diallyl sulfide (DAS), Diallyl disulfide } \\
\text { (DADS), Diallyltrisulfide (DATS), } \\
\text { dipropyl sulfide, diproyltrisulfide. }\end{array}$ & $\begin{array}{l}\text { Inhibition of cholesterol synthesis by } 40-60 \\
\text { percent. }\end{array}$ & {$[42]$} \\
\hline Alliin and allicin. & $\begin{array}{l}\text { Inhibition of hepatic hydroxyl } \\
\text { methylglutaryl-CoA reductase activity. }\end{array}$ & [78] \\
\hline Alliin and allicin derived thiosulfinates. & Antithrombotic activity. & [48] \\
\hline
\end{tabular}

Source: Ugwu and Suru [14].

their varied bioactive contents [19].

Garlic is well known powerful anti-atherogenic supplement [20]. Many reports have evaluated the effectiveness of garlic extracts/bioactive components in protection against CVD. The report of Mikaili et al. [21] indicate that garlic could directly ameliorate atherosclerosis by its capacity to reduce arterial cell lipid content, inhibit intracellular lipid accumulation as well as the inhibition of lipogenic and cholesterogenic hepatic enzymes activities [22]. Garlic extracts and fractions have the potential to prevent diet-induced hypercholesterolemia in cholesterol-fed rats and mice [23]-[25] and known to reduce the ratio of serum LDL to HDL [24] [26]. Garlic powder was reported to reduce total cholesterol and low density lipoprotein (LDL) cholesterol [27] (Figure 1).

Garlic extracts have been variously reported to have anti-hypertensive effects by increasing NO synthesis [28], induction of vasodilatation with hydrogen sulphide [29], and inhibition of angiotensin converting enzyme activity. The report of ZahidAshraf et al. [30] indicated that garlic extract is a vasorelaxant and may reduce the atherogenic potentials of cholesterol in rats.

Fallon et al. [31] reported that garlic inhibited acute hypoxic pulmonary vasoconstriction in rats and elicited appreciable dose-dependent vasorelaxation in both endothelium-intact and mechanically endothelium-disrupted pulmonary arterial rings. This implies that it can combine both endothelium-dependent and independent process in its hypotensive property [31] [32]. In vitro study by [33] indicated that garlic juice can relax the muscles of aorta, trachea, intestines and isolated rabbit heart. Garlic can also block $\beta$-adrenoreceptor-blocking action by providing a depressing effect on automaticity and tension development in isolated rat heart [34]. The dose-dependent effect of 
garlic on the kidney $\mathrm{Na}$, K-ATPase and diuretic and natriuretic response may partly explain the hypotensive effect of garlic bioactive constituents [35]-[37]. Allicin, ajone, cicletane and other sulphur-containing compounds in garlic may be responsible for the hypotensive property of garlic [32] (Figure 2).

Aged garlic extract (AGE) has been reported to prevent lipid oxidation and oxidative modification of LDL, thereby decreasing the amount of oxidized LDL in circulation and the subsequent build-up of cholesterol in macrophages, smooth muscles and blood vessel walls, leading to the inhibition of atherogenic fatty streaks [17] [18]. These properties, joined with other known activities of AGE, enhance its ability to reduce the risk of cardiovascular and cerebrovascular disease. Other protective actions of AGE include inhibition of platelet aggregation and suppression of prostanoid synthesis with subsequent anti-inflammatory, anti-atherogenic and anti-thrombotic effects [38].

The protection of endothelial cell integrity via the prevention of lipid peroxidative injury and reduction in serum cholesterol and other oxidizable lipids by AGE adds to its

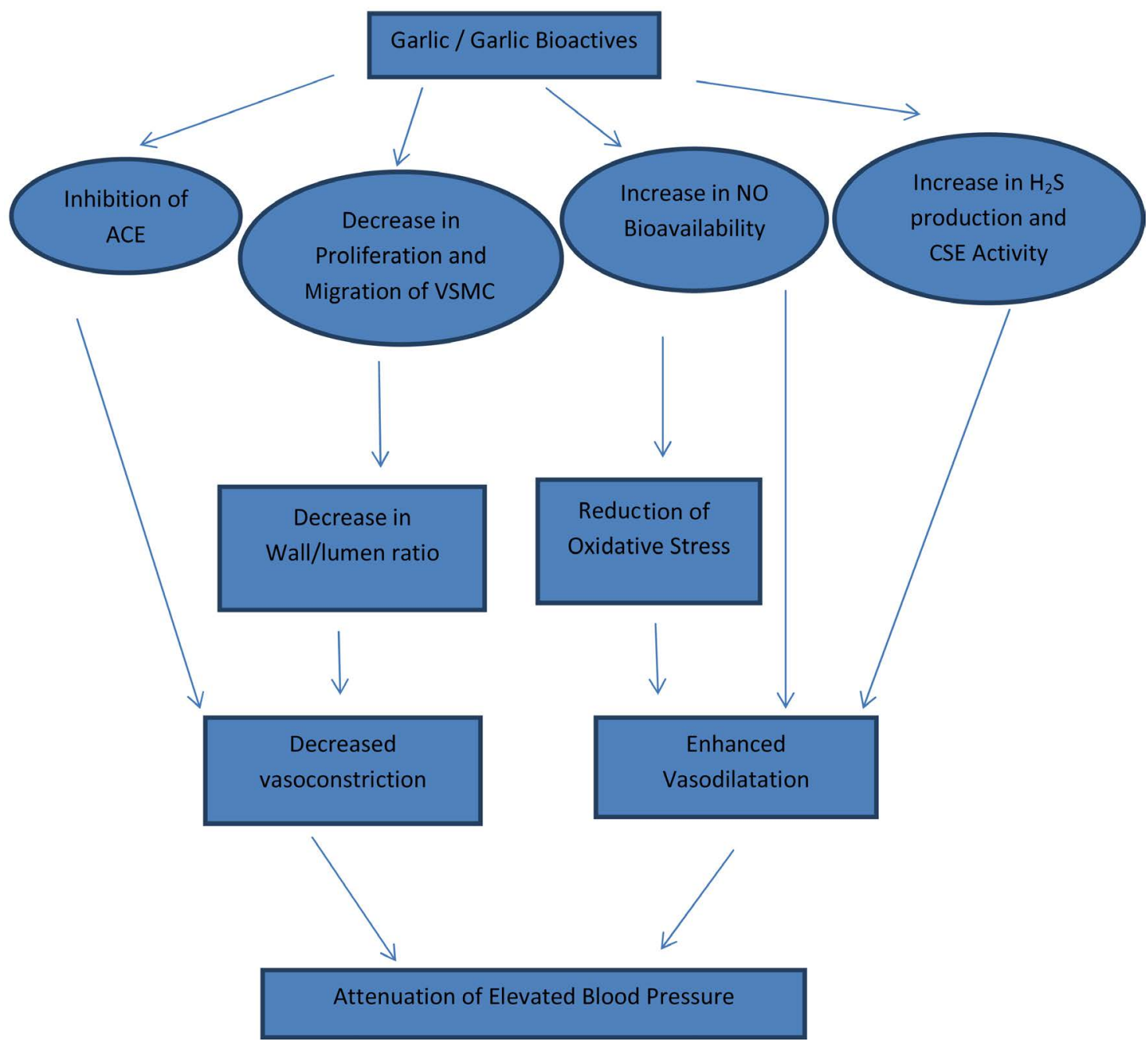

Figure 3. Putative mechanisms underlying the potential roles of garlic bioactives for hypertension management. Source: Shouk et al. [76]. 
functional capacity in providing protection against heart disease and stroke [19] [39]. Free radical damage and inflammatory processes, linked to enhanced levels of eicosanoids, play an important role in cerebral ischemia-reperfusion injury. Peroxynitrite, a product of superoxide and nitric oxide interactions, is thought to be a major injurious agent, inducing lipid peroxides and tissue damage [40]. AGE and its constituent SAC showed a dose-related attenuation of ROS production and inhibition of brain damage caused by ischemia-reperfusion and reducing post-ischemia oedema [41].

\section{Bioactive Constituents with Cardiovascular and Cerebrovascular Health Effects}

Many of the bioactive constituents in garlic and AGE have been shown to elicit cardiovascular health benefits (Figure 3 and Table 1). Diallyl disulfide and diallyl trisulfide have been reported by Lei et al. [7] to suppress oxidized LDL-induced vascular cell adhesion. In both human and animal studies, the water and lipid soluble constituents in garlic inhibited cholesterol synthesis [42]. Allyl methyl sulfide (AMS) and diallyl sulfide (DAS) are efficient antioxidant bioactive constituents in garlic that have been shown to improve structural changes resulting from hypertension [43]. More so, Cruz et al. [44] reported that S-allyl cysteine (SAC) caused a reduction in hypertension and renal damage in nephrectomized rats via its antioxidant property (Figure 2).

Diallyl trisulfide (DATS) has been shown to have antithrombotic activity [45] while methyl allyl trisulfide (MATS) is known to inhibit anti-platelet activity via inhibition of arachidonic acid cascade [46]. Ajoene possesses anti-aggregatory property that is linked to its direct interaction with putative fibrinogen receptors [47] and irreversibly inhibits platelet aggregation initiated by arachidonic acid [48].

Reports on the cardiovascular benefits of other garlic bioactive constituents show that allicin could positively affect two atherosclerotic risk factors: preventing the uptake of LDL and breaking down of macrophages [49] [50]. More so, several in vitro and in vivo reports tend to suggest that garlic constituents and its extract elicit antithrombotic effects. Allicin and its derived thiosulfinates are proposed as the principal bioactive constituents responsible for the antithrombotic effect of garlic [51]. Allicin and aromatic thiosulfonate are known to be the major anti-platelet compounds of garlic extract [52] [53].

Allicin could also exhibit hypotensive properties as reported in the studies where its oral administration to rats with arterial hypertension leads to a marked hypotensive effect [54]. Allicin is believed to be a systematic vasodilator prostacyclin synthase but dilates the mesenteric circulation in cats independent of prostaglandin release or $\beta$ adrenergic mechanism [32]. Allicin from garlic powder has the potential to induce hypotension in rabbit eye by acting on the neuroeffector junction [55]. Garlic oil has been reported to reduce systolic and diastolic blood pressure and oxidized LDL in hypertensive patients [56].

Many studies have shown that in clinical trials with hypertensive subjects, garlic supplements have the potential to lower blood pressure [4] [57] [58]. The report of Reid et 
al. [59] has shown that aged garlic extract containing $1.2 \mathrm{mg}$ of S-allyl cysteine was effective in lowering peripheral and central blood pressure in patients with uncontrolled hypertension. They also reported that AGE improves other cardiovascular risk factors like arterial stiffness and inflammatory markers $\mathrm{TNF}_{\alpha}$, total cholesterol, LDL-c and apolipoproteins [59]. Garlic extract has previously been reported to lower the proinflammatory markers, IL-1B and $\mathrm{TNF}_{\alpha}$ and levels of oxidized LDL in in vitro studies [60].

A meta-analysis of 39 or 20 trials reported that garlic effectively reduced in $10 \%$ of people with slightly elevated levels of total cholesterol and LDL-c [58]. The systematic review and meta-analysis by Reid et al. [57] suggested that garlic preparations are superior to placebo in reducing blood pressure in subjects with hypertension. Most studies included in this review used garlic powder dosages of 600 - $900 \mathrm{mg}$ per day, providing potentially 3.6 - $5.4 \mathrm{mg}$ of allicin, the active compound in garlic [61]. In comparison fresh garlic cloves (appr.2g) each yield 5 - $9 \mathrm{mg}$ allicin [62]. AGE is adapted for use in treatment of blood pressure because it has the standardized active and stable component S-allylcysteine [4]. Reid et al. [58] reported that AGE containing S-allylcysteine was superior to placebo in patients with uncontrolled hypertension.

The results of Grazyna et al. [63] failed to confirm a clear-cut hypotensive potential of allicin derivatives (vinyl-dithiins) that was the key potent ingredient in their garlic preparation. Some authors have linked the hypotensive effect of garlic on $\gamma$-glutamyl cysteine and fructans that inhibit the activity of angiotensin-converting enzyme, induce nitrogen oxidase synthetase and control the production of and action of vasoconstricting and vasodilatory substances found in vascular endothelium [63] [64].

The result of Sobenin et al. [32] show that time-released garlic powder tablets are more effective for the treatment of mild and moderate arterial hypertension than regular garlic supplements. Results from animal studies indicate that bioactive constituents in garlic can lower blood pressure in hypertensive animals by inducing vasodilating effects at the level of the arterial wall [65]. Garlic can prevent L-NAME-induced arterial hypertension in rat by chronically inhibiting nitric oxide synthesis by L-NAME (Nomega-nitro-L-arginine methyl ester) [66].

The study of Nwokocha et al. [67] showed that AGE induced a decrease in blood pressure and bradycardia without involving the cholinergic pathway implying that its antihypertensive activity may involve the peripheral mechanism. It has also been demonstrated that short-term supplementation with garlic has antioxidant and hypolipidemic activity in hypertensive subjects [68].

The role of garlic in the prevention of ischemia-reperfusion injury can be demonstrated by its inhibition of angiotensin converting enzyme action thereby contributing to cardioprotective and blood pressure lowering effects [69]. A study by Ali et al. [49] showed that allicin from garlic powder has both hypolipidaemic and hypotensive effects in rats fed with a high cholesterol diet. Chu et al. [55] reported that allicin induced hypotension in rabbit eyes by dual actions at the neuro-effector junction. Garlic extract was reported to induce dose dependent and reversible hypotensive and bradycardic ef- 
fects [70]. The cardioprotective effects of garlic are mainly through the generation of hydrogen sulphide [21]. In the erythrocytes, the garlic derived sulphur compounds are converted into hydrogen sulphide that relaxes vascular smooth muscle, vasodialates blood vessels and thereby reducing blood pressure [29]. The antihypertensive and renoprotective effects of SAC and AGE suggest that they may be used to control hypertension and delay progression of renal damage [44]. Two other sulphur derivatives in garlic extract (allyl methyl sulphide (AMS) and diallyl sulphide (DAS) were demonstrated by Castro et al. [43] to inhibit migration and angiotensin II-stimulated cell cycle progression in smooth muscle cell of aorta. Consequently AMS and DAS could be deployed as a potent antioxidant against arterial structural changes caused by hypertension [43].

The AGE improved blood pressure in spontaneously hypertensive (SHR) rats better than raw garlic [71]. Other reports indicate that in SHRs [72] and humans [73] garlic improved blood pressure. The lowering effect of garlic on SHRs was linked to the nitric oxide system being more effective than the renin-angiotensin system [71]. The report of Harauma and Moriguachi [71] suggests that one of the systolic blood pressure-lowering effects of AGE could be by protection and maintenance of the flexibility in the blood vessel and the improvement of erythrocyte deformability.

\section{Gaps to Be Filled}

Significant synergy or antagonism of the garlic substances, or their derivatives, on human physiology may exist and vary with an individual's age, pathology, dosage regimen and possible drug, food or metabolite interactions. The mode of garlic preparations determines its effectiveness on blood pressure. For instance, minimal allicin compounds are seen in AGE or heat-treated garlic preparations, which could reduce its hypotensive properties [74]. Therefore, it is suggestive for researchers to use standardized preparations in their experimental trials. When comparing different results that tested the efficacy of garlic products on blood pressure, the dosage of S-allyl cysteine in AGE is crucial for proper comparison [58]. The trial quality on the effect of garlic on blood pressure is important in determining the effect of garlic on blood pressure. This is because previous meta-analysis were based on trials with poor study design [75].

\section{Conclusion}

This review has tried to harmonize contemporary research on the role of garlic bioactive constituents in the prevention and treatment of cardiovascular diseases. There is the need to harmonize the garlic preparations for better validation of therapeutic claims.

\section{References}

[1] Mendis, S., Puska, P., Norrving, B. and World Health Organization (2011) Global Atlas on Cardiovascular Disease Prevention and Control. World Health Organization in Collaboration with the World Heart Federation and the World Stroke Organization. 3-18. 
www.nhs.uk

[2] Ross, R. (1999) Atherosclerosis-An Inflammatory Disease. New England Journal of Medicine, 340, 115-126. http://dx.doi.org/10.1056/NEJM199901143400207

[3] Briganti, E.M., McNell, J.J., Shaw, J.E., Zimmet, P.Z., Chadban, S.J., Atkins, C.R., et al. (2003) Untreated Hypertension among Australian Adults: The 1999-2000 Australian Diabetes, Obesity and Lifestyle Study (AusDiab). Medical Journal of Australia, 179,135-139.

[4] Ried, K., Frank, O.R. and Stocks, N.P. (2010) Aged Garlic Extract Lowers Blood Pressure in Patients with Treated but Uncontrolled Hypertension: A Randomised Controlled Trial. Maturitas, 67, 144-150. http://dx.doi.org/10.1016/j.maturitas.2010.06.001

[5] Amagase, H. (2006) Clarifying the Real Bioactive Constituents of Garlic. Journal of Nutrition, 136, 716S-725S.

[6] Prette, N., Monteiro, A.C., Garcia, M.V. and Soares, V.E. (2005) Patogenicidade de isolados de Beauveria bassiana para ovos, larvas e ninfas ingurgitadas de Rhipicephalus sanguineus. Ciênc Rural, 35, 855-861. http://dx.doi.org/10.1590/S0103-84782005000400017

[7] Lei, Y., Chen, H., Sheen, L. and Lii, C. (2008) Diallydisulfide and Diallyltrisulfide Suppress Oxidized LDL-Induced Vascular Cell Adhesion Molecule and E-Selectin Expression through Protein Kinase A- and B-Dependent Signalingpathways. Journal of Nutrition, 138, 9961003.

[8] Santhosha, S.G., Jamuna, P. and Prabhavathi, S.N. (2013) Bioactive Components of Garlic and Their Physiological Role in Health Maintainance: A Review. Food Bioscience, 3, 59-74. http://dx.doi.org/10.1016/j.fbio.2013.07.001

[9] Lancaster, J.E. and Shaw, M.L. (1989) $\gamma$-Glutamyl Peptides in the Biosynthesis of S-alk(en)ylL-cysteine Sulfoxides (Flavour Precursors) in Allium. Phytochemistry, 28, 455-460. http://dx.doi.org/10.1016/0031-9422(89)80031-7

[10] Amagase, H., Petesch, B.L., Matsuura, H., Kasuga, S. and Itakura, Y. (2001) Intake of Garlic and Its Bioactive Components. Journal of Nutrition, 131, 955S-962S.

[11] Fenwick, G.R. and Hanley, A.B. (1985) The Genus Allium. Part 2. Critical Review in Food Science and Nutrition, 22, 273-377. http://dx.doi.org/10.1080/10408398509527417

[12] Staba, E., Staba, J., Lash, L. and Staba, J.E. (2001) A Commentary on the Effects of Garlic Extraction and Formulation on Product Composition. Journal of Nutrition, 131, 1118S1119 S.

[13] Rahman, K. and Lowe, G.M. (2006) Garlic and Cardiovascular Disease: A Critical Review. Journal of Nutrition, 136, 736S-740S.

[14] Ugwu, C.E. and Suru, S.M. (2016) Medicinal Use and Health Benefits of Allium sativum: A Comparative Review of the Whole Extract vs Bioactive Constituents. In: Haynes, A., Ed., Allium sativum Chemical Constituents, Medicinal Uses and Health Benefits, Nova Science Publishers, New York, 43-69.

[15] Cox, D.A. and Cohen, M.L. (1996) Effects of Oxidized Low Density Lipoproteins on Vascular Contraction and Relaxation: Clinical and Pharmacological Implications in Atherosclerosis. Pharmacology Review, 48, 3-9.

[16] Witztum, J.L. (1993) Role of Oxidized Low Density Lipoproteins in Atherogenesis. British Heart Journal, 69, S12-S18. http://dx.doi.org/10.1136/hrt.69.1_Suppl.S12

[17] Efendy, J.L., Simmons, D.L., Campbell, G.R. and Campbell, J.H. (1997) The Effect of the Aged Garlic Extract, "Kyolic", on the Development of Experimental Atherosclerosis. Atherosclerosis, 132, 37-42. http://dx.doi.org/10.1016/S0021-9150(97)00078-6

[18] Ide, N. and Lau, B.H.S. (1997) Garlic Compounds Protect Vascular Endothelial Cells from 
Oxidized Low Density Lipoprotein-induced Injury. Journal of Pharmacy and Pharmacology, 49, 908-911. http://dx.doi.org/10.1111/j.2042-7158.1997.tb06134.x

[19] Borek, C. (2001) Antioxidant Health Effects of Aged Garlic Extract. Journal of Nutrition, 131, 1010S-1015S.

[20] Gorinstein, S., Jastrzebski, Z., Namiesnik, J., Leontowicz, H., Leontowicz, M. and Trakhtenberg, S. (2007) The Atherosclerotic Heart Disease and Protecting Properties of Garlic: Contemporary Data. Molecular Nutrition and Food Research, 51, 1365-1381. http://dx.doi.org/10.1002/mnfr.200700064

[21] Mikaili, P., Maadirad, S., Moloudizargari, M., Aghajanshakeri, S. and Sarahroodi, S. (2013) Therapeutic Uses and Pharmacological Properties of Garlic, Shallot, and Their Biologically Active Compounds. Iranian Journal of Basic Medical Sciences, 16, 1031-1048.

[22] Mathew, B. and Biju, R. (2008) Neuroprotective Effects of Garlic: A Review. Libyan Journal of Medicine, 3, 23-33. http://dx.doi.org/10.4176/071110

[23] Slowing, K., Ganado, P., Sanz, M., Ruiz, E. and Tejerina, T. (2001) Study of Garlic Extracts and Fractions on Cholesterol Plasma Levels and Vascular Reactivity in Cholesterol-Fed Rats. Journal of Nutrition, 131, 994S-999S.

[24] Mahmoodi, M., Islami, M.R., Asadi Karam, G.R., Khaksari, M., Sahebghadam Lotfi, A., Hajizadeh, M.R., et al. (2006) Study of the Effects of Raw Garlic Consumption on the Level of Lipids and Other Blood Biochemical Factors in Hyperlipidemic Individuals. Pakistan Journal of Pharmaceutical Sciences, 19, 295-298.

[25] Mohammadi, A. and Oshaghi, E.B. (2014) Effect of Garlic on Lipid Profile and Expression of LXR alpa in Intestine and Liver of Hypercholesterolemic Mice. Journal of Diabetes and Metabolic Disorders, 13, 20. http://dx.doi.org/10.1186/2251-6581-13-20

[26] Ebrahimi, T., Behdad, B., Abbsi, M.A., Rabati, R.G., Fayyaz, A.F., Behnod, V. and Asgari, A. (2015) High Dose of Garlic Extract Significantly Attenuated the Ratio of Serum LDL to HDL Level in Rats-Fed with Hypercholesterolemia Diet. Diagnostic Pathology, 10, 74. http://dx.doi.org/10.1186/s13000-015-0322-0

[27] Sobenin, I.A., Pryanishnikov, V.V., Kunnova, L.M., Rabinovich, Y.A., Martirosyan, D.M. and Orekhov, A.N. (2010) The Effects of Time-Released Garlic Powder Tablets on Multifunctional Cardiovascular Risk in Patients with Coronary Artery Disease. Lipids in Health and Diseases, 9, 119. http://dx.doi.org/10.1186/1476-511X-9-119

[28] AL-Quattan, K.K., Thomson, M., AL-Musawa'a, S., AL-Hajeri, D., Drobiova, H. and Ali, M. (2006) Nitric Oxide Mediates the Blood Pressure Lowering Effect of Garlic in the Rat Two-Kidney, One-Clip Model of Hypertension. Journal of Nutrition, 136, 774S-776S.

[29] Ginter, E. and Simko, V. (2010) Garlic (Allium sativum L) and Cardiovascular Diseases. BratislLekListy, 111, 452-456.

[30] Zahid Ashraf, M., Hussain, M.E. and Fahim, M. (2005) Antiatherosclerotic Effects of Dietary Supplementations of Garlic and Turmeric Restoration of Endothelial Function in Rats. Life Science, 77, 837-857. http://dx.doi.org/10.1016/j.lfs.2004.11.039

[31] Fallon, M.B., Abrams, G.A., Abdel-Razek, T.T., Dai, J., Chen, S.J., Chen, Y.F., et al. (1998) Garlic Prevents Hypoxic Pulmonary Hypertension in Rats. American Journal of Physiology, 275, 283-287.

[32] Sobenin, I.A., Andrianova, I.V., Fomchenkov, I.V., Gorchakova, T.V. and Orekhov, A.N. (2009) Time-Released Garlic Powder Tablets Lower Systolic and Diastolic Blood Pressure in Men with Mild and Moderate Arterial Hypertension. Hypertension Research, 32, 433437. http://dx.doi.org/10.1038/hr.2009.36

[33] Aqel, M.B., Gharaibah, M.N. and Salhab, A.S. (1991) Direct Relaxant Effects of Garlic Juice 
on Smooth and Cardiac Muscles. Journal of Ethnopharmacology, 33, 13-19. http://dx.doi.org/10.1016/0378-8741(91)90154-6

[34] Martin, N., Bardisa, L., Pantoja, C.V., Roman, R. and Vargas, M. (1992) Experimental Cardiovascular Depressant Effects of Garlic (Allium sativum) Dialysate. Journal of Ethnopharmacology, 37, 145-149. http://dx.doi.org/10.1016/0378-8741(92)90072-Y

[35] Pantoja, C.V., Chiang, L.C., Norris, B.C. and Concha, J.B. (1991) Diuretic, Natriuretic and Hypotensive Effects Produced by Allium sativum (Garlic) in Anaesthetized Dogs. Journal of Ethnopharmacology, 31, 325-331. http://dx.doi.org/10.1016/0378-8741(91)90018-9

[36] Pantoja, C.V., Norris, B.C. and Contreras, C.M. (1996) Diuretic and Natriuretic Effects of Chromatographically Purified Fraction of Garlic (Allium sativum). Journal of Ethnopharmacology, 52, 101-105. http://dx.doi.org/10.1016/0378-8741(96)01396-7

[37] Pantoja, C.V., Martin, N.T., Norris, B.C. and Contreras, C.M. (2000) Purification and Bioassays of Adiuretic and Natriuretic Fraction from Garlic (Allium sativum). Journal of Ethnopharmacology, 70, 35-40. http://dx.doi.org/10.1016/S0378-8741(99)00145-2

[38] Dimitrov, N.V. and Bennink, M.R. (1997) Modulation of Arachidonic Acid Metabolism by Garlic Extract. In: Lanchance, P.P., Ed., Nutraceuticals. Designer Foods III Garlic, Soy and Licorice, Food and Nutrition Press, Trumbull, 199-120.

[39] Weiss, N., Ide, N., Abahji, T., Nill, L., Keller, C. and Hoffmann, U. (2006) Aged Garlic Extract Improves Homocysteine-Induced Endothelial Dysfunction in Macro- and Microcirculation. Journal of Nutrition, 136, 750S-754S.

[40] Beckman, J.S. (1991) The Double Edged Sword of Nitric Oxide in Drain Function and Superoxide Mediated Injury. Journal of Developmental Physiology, 15, 53-59.

[41] Numagami, Y. and Ohnishi, S.T. (2001) S-Allylcysteine Inhibits Free Radical Production, Lipid Peroxidation and Neuronal Damage in Rat Brain Ischemia. Journal of Nutrition, 131, 1100S-1105S.

[42] Yeh, Y. and Liu, L. (2001) Cholesterol Effect of Garlic Extracts and Organosulfur Compounds: Human and Animal Studies. Journal of Nutrition, 131, 989S-993S.

[43] Castro, C., Lorenzo, A.G., González, A. and Cruzado, M. (2010) Garlic Components Inhibit Angiotensin II-Induced Cell-Cycle Progression and Migration: Involvement of Cell-Cycle Inhibitor p2 $7^{\text {Kipl }}$ and Mitogen-Activated Protein Kinase. Molecular Nutrition and Food Research, 54, 781-787. http://dx.doi.org/10.1002/mnfr.200900108

[44] Cruz, C., Correa-Rotter, R., Sánchez-González, D.J., Hernández-Pando, R., Maldonado, P.D., Martínez-Martínez, C.M., et al. (2007) Renoprotective and Antihypertensive Effects of S-Allylcysteine in 5/6 Nephrectomized Rats. American Journal of Physiology, Renal Physiology, 293, F1691-F1698. http://dx.doi.org/10.1152/ajprenal.00235.2007

[45] Choi, Y.H. and Park, H.S. (2012) Apoptosis Induction of U937 Human Leukemia Cells by Diallyl Trisulfide Induces through Generation of Reactive Oxygen Species. Journal of Biomedical Sciences, 19, 50. http://dx.doi.org/10.1186/1423-0127-19-50

[46] Ariga, T., Tsuj, K., Seki, T., Moritomo, T. and Yamamoto, J.I. (2000) Antithrombotic and Antineoplastic Effects of Phyto-Organosulfur Compounds. BioFactors, 13, 251-255. http://dx.doi.org/10.1002/biof.5520130138

[47] Apitz-Castro, R., Ledezma, E., Escalante, J. and Jain, M.K. (1986) The Molecular Basis of the Antiplatelet Action of Ajoene: Direct Interaction with the Fibrinogen Receptor. Biochemical and Biophysical Research Communications, 141, 145-150. http://dx.doi.org/10.1016/S0006-291X(86)80346-1

[48] Srivastava, K.C. and Tyagi, O.D. (1993) Effects of a Garlic-Derived Principle (Ajoene) on Aggregation and Arachidonic Acid Metabolism in Human Blood Platelets. Prostaglandins, 
Leukotrienes and Essential Fatty Acids, 49, 587-595.

http://dx.doi.org/10.1016/0952-3278(93)90165-S

[49] Ali, M., Al-Qattan, K.K., Al-Enezi, F., Khanafer, R.M. and Mustafa, T. (2000) Effect of Allicin from Garlic Powder on Serum Lipids and Blood Pressure in Rats Fed with a High Cholesterol Diet. Prostaglandins, Leukotrienes and Essential Fatty Acids, 62, 253-259. http://dx.doi.org/10.1054/plef.2000.0152

[50] Gonen, A., Harat, D., Rabinkov, A., Miron, T., Mirelman, D., Wilchek, M., et al. (2005) The Antiatherogenic Effect of Allicin: Possible Mode of Action. Pathobiology, 72, 325-334. http://dx.doi.org/10.1159/000091330

[51] Cavagnaro, P.F., Camargo, A., Galmarini, C.R. and Simon, P.W. (2007) Effect of Cooking on Garlic (Allium sativum L.) Antiplatelet Activity and Thiosulfinates Content. Journal of Agricultural and Food Chemistry, 55, 1280-1288. http://dx.doi.org/10.1021/jf062587s

[52] Agarwal, K.C. (1996) Therapeutic Actions of Garlic Constituents. Medicinal Research Reviews, 16, 111-124. http://dx.doi.org/10.1002/(SICI)1098-1128(199601)16:1<111::AID-MED4>3.0.CO;2-5

[53] MacDonald, J.A., Marchand, M.E. and Langler, R.F. (2004) Improving upon the in Vitro Biological Activity of Antithrombotic Disulfides. Blood Coagulation and Fibrinolysis, 15, 447-450. http://dx.doi.org/10.1097/00001721-200408000-00002

[54] Banerjee, J.S. and Maulike, S.K. (2009) Effect of Garlic on Cardiovascular Disorders: A Review. Journal of Nutrition, 1, 1-14.

[55] Chu, T.C., Ogidigben, M., Han, J.C. and Potter, D.E. (1993) Allicin-Induced Hypotension in Rabbit Eyes. Journal of Ocular Pharmacology and Therapeutics, 9, 201-209. http://dx.doi.org/10.1089/jop.1993.9.201

[56] Dhawan, V. and Jain, S. (2004) Effect of Garlic Supplementation on Oxidized Low Density Lipoproteins and Lipid Peroxidation in Patients of Essential Hypertension. Molecular and Cellular Biochemistry, 266, 109-115. http://dx.doi.org/10.1023/B:MCBI.0000049146.89059.53

[57] Ried, K., Frank, O.R., Stocks, N.P., Fakler, P. and Sullivan, T. (2008) Effect of Garlic on Blood Pressure: A Systematic Review and Meta-Analysis. BMC Cardiovascular Disorder, 8, 13. http://dx.doi.org/10.1186/1471-2261-8-13

[58] Ried, K., Frank, O.R. and Stocks, N.P. (2013) Aged Garlic Extract Reduces Blood Pressure in Hypertensives: A Dose-Response Trial. European Journal of Clinical Nutrition, 67, 64-70. http://dx.doi.org/10.1038/ejcn.2012.178

[59] Ried, K., Travica, N. and Sali, A. (2016) The Effect of Aged Garlic Extract on Blood Pressure and Other Cardiovascular Risk Factors in Uncontrolled Hypertensives: The AGE at Heart Trial. Integrated Blood Pressure Control, 9, 9-21. http://dx.doi.org/10.2147/IBPC.S93335

[60] Keiss, H.P., Dirsch, V.M., Hartung, T., et al. (2003) Garlic (Allium sativum L) Modulates Cytokine Expression in Lipopolysaccharide-Activated Human Blood Thereby Inhibiting NF- $\kappa$ B Activity. Journal of Nutrition, 133, 2171-2175.

[61] Ackermann, R.T., Mulrow, C.D., Ramirez, G., Gardner, C.D., Morbidoni, L. and Lawrence, V.A. (2001) Garlic Shows Promise for Improving Some Cardiovascular Risk Factors. Archives of Internal Medicine, 161, 813-824. http://dx.doi.org/10.1001/archinte.161.6.813

[62] Lawson, L. (1998) Garlic: A Review of Its Medicinal Effects and Indicated Active Compounds. In: Lawson, L. and Bauer, R., Eds., Phytomedicines of Europe: Chemistry and Biological Activity, American Chemical Society, Washington DC, 177-209. http://dx.doi.org/10.1021/bk-1998-0691.ch014 
[63] Grazyna, D., Joanna, S. and Danuta, P. (2008) Effects of Short-Term Garlic Supplementation on Lipid Metabolism and Antioxidant Status in Hypertensive Adults. Pharmacological Report, 60, 163-170.

[64] Blumenthal, M., Hall, T., Goldberg, A. and Kunz, T. (2003) The ABC Clinical Guide to Herbs. American Botanical Council, Austin.

[65] Foushee, D.B., Ruffin, J. and Banerjee, U. (1982) Garlic as a Natural Agent for the Treatment of Hypertension: A Preliminary Report. Cytobios, 34, 145-152.

[66] Pedraza Chaverri, J., Tapia, E., Medina Campos, O.N., de los Angeles Granados, M. and Franco, M. (1998) Garlic Prevents Hypertension Induced by Chronic Inhibition of Nitric Oxide Synthesis. Life Sciences, 62, PL71-PL77. http://dx.doi.org/10.1016/S0024-3205(97)01155-7

[67] Nwokocha, C.R., Ozolua, R.I., Owu, D.U., Nwokocha, M.I. and Ugwu, A.C. (2011) Antihypertensive Properties of Allum sativum (Garlic) on Normotensive and Two Kidney One Clip Hypertensive Rats. Nigerian Journal of Physiological Sciences, 26, 213-218.

[68] Duda, G., Suliburska, I. and Pupek-Musialik, D. (2008) Effects of Short-Term Garlic Supplementation on Lipid Metabolism and Oxidative Status in Hypertensive Adults. Pharmacological Reports, 60, 163-170.

[69] Sener, G., Sakarcan, A. and Yegen, B.C. (2007) Role of Garlic in the Prevention of Ischemia-Reperfusion Injury. Molecular Nutrition and Food Research, 51, 1345-1352. http://dx.doi.org/10.1002/mnfr.200700078

[70] Brankovic, S., Radenkovic, M., Kitic, D., Veljkovic, S., Ivectic, V., Pavlovic, D., et al. (2011) Comparison of the Hypotensive and Bradycardic Activity of Ginkgo, Garlic, and Onion Extracts. Clinical and Experimental Hypertension, 33, 95-99. http://dx.doi.org/10.3109/10641963.2010.531833

[71] Harauma, A and Moriguchi, T. (2006) Aged Garlic Extract Improves Blood Pressure in Spontaneously Hypertensive Rats More Safely than Raw Garlic. Journal of Nutrition, 136, 769S-773S.

[72] Mohamadi, A., Jarrell, S.T., Shi, S.J., Andrawis, N.S., Myers, A., Clouatre, D., et al. (2000) Effects of Wild Versus Cultivated Garlic on Blood Pressure and Other Parameters in Hypertensive Rats. Heart Disease, 2, 3-9.

[73] Steiner, M., Khan, A.H., Holbert, D. and Lin, R.I. (1996) A Double-Blind Crossover Study in Moderately Hypercholesterolemic Men That Compared the Effect of Aged Garlic Extract and Placebo Administration on Blood Lipids. American Journal of Clinical Nutrition, 64, 866-870.

[74] Benerjee, S.K., Mukherjee, P.K. and Maulik, S.K. (2003) Garlic as an Antioxidant: The Good, the Bed and the Ugly. Phytotherapy Research, 17, 97-106. http://dx.doi.org/10.1002/ptr.1281

[75] Simons, S., Wollersheim, H. and Thien, T. (2009) A Systematic Review on the Influence of Trial Quality on the Effect of Garlic on Blood Pressure. The Netherlands Journal of Medicine, 67, 212-219.

[76] Shouk, R., Abdou, A., Shetty, K., Sarkar, D. and Eid, A.H. (2014) Mechanisms Underlying the Anti-Hypertensive Effects of Garlic Bioactives. Nutrition Research, 34, 106-115. http://dx.doi.org/10.1016/j.nutres.2013.12.005

[77] Asdaq, S.M. and Inamdar, M.N. (2010) Potential of Garlic and Its Active Constituent, S-Allyl Cysteine, as Antihypertensive and Cardioprotective in Presence of Captopril. Phytomedicine, 17, 1016-1026. http://dx.doi.org/10.1016/j.phymed.2010.07.012

[78] Sangeetha, T. and Darlin Quine, S. (2006) Preventive Effect of S-Allyl Cysteine Sulfoxide 
(Alliin) on Cardiac Marker Enzymes and Lipids in Isoproterenol-Induced Myocardial Injury. Journal of Pharmacy and Pharmacology, 58, 617-623.

http://dx.doi.org/10.1211/jpp.58.5.0006

\section{Abbreviation Note}

Cardiovascular disease-CVD.

Coronary artery diseases-CAD.

Organosulfur compound-OSC.

Aged garlic extract-AGE.

S-allyl cysteine-SAC.

S-ethyl cysteine-SEC.

S-propyl cysteine-SPC.

$\gamma$-glutarmyl-S-allyl cysteine-GSAC.

$\gamma$-glutarmyl-S-methyl cysteine-GSMC.

$\gamma$-glutarmyl-S-propyl cysteine-GSPC.

Diallyl sulfide-DAS.

Diallyl disulfide-DADS.

Diallyltrisulfide-DATS.

Methylallyltrisulfide-MATS.

$\mathrm{N}$-omega-nitro-L-arginine methyl ester-L-NAME.

Spontaneously hypertensive rats-SHR. 
Submit or recommend next manuscript to SCIRP and we will provide best service for you:

Accepting pre-submission inquiries through Email, Facebook, LinkedIn, Twitter, etc. A wide selection of journals (inclusive of 9 subjects, more than 200 journals)

Providing 24-hour high-quality service

User-friendly online submission system

Fair and swift peer-review system

Efficient typesetting and proofreading procedure

Display of the result of downloads and visits, as well as the number of cited articles

Maximum dissemination of your research work

Submit your manuscript at: http://papersubmission.scirp.org/

Or contact jbm@scirp.org 